\title{
THE PREVENTION OF ACCIDENTS IN CHILDHOOD IN SWEDEN*
}

BY

\author{
TH. EHRENPREIS \\ Stockholm, Sweden
}

The problem of accidents in childhood has aroused considerable interest in Sweden during the last few years. The impressive figures on accidental deaths in childhood provided by mortality statistics brought about, in 1954, the constitution of a Joint Committee for the Prevention of Childhood Accidents, including representatives of a number of interested organizations (the Red Cross, Save the Children Fund, National Society for Road Safety, Swedish Fire Protection Association, the Association for Promoting Elementary Swimming, Board of Health, Board of Education, Association of Nurses, women's organizations, etc.). Two medical advisers were attached to this Committee, one a paediatrician with a special interest in social paediatrics (Dr. R. Berfenstam, Upsala) and the other a paediatric surgeon (Dr. Th. Ehrenpreis).

The principal aims of this Committee have been to incite studies of the problem, to promote safety measures and to inform the public.

\section{Accident Studies}

Mortality statistics show a remarkable decrease in infant and childhood mortality during the last decades. The various causes of death do, however, play a very different part in this decrease. The most spectacular improvement has been attained within the group of infectious diseases, whereas accidental death has diminished only slightly. This has resulted in a gradual increase in the proportion of accidental deaths in childhood as shown in Fig. 1 prepared from Swedish mortality statistics.

Except for the facts provided by mortality statistics, we know very little about the epidemiology of accidents in childhood. Clinical experience seems to indicate that although there is no actual increase in accident mortality, there is probably a definite increase in accident morbidity. Another experience that emerges from daily work with injured children is that accidents to a large extent are preventable.

It was keenly felt that a better knowledge of accident morbidity in childhood would be a prerequisite to all kinds of preventive measures. As

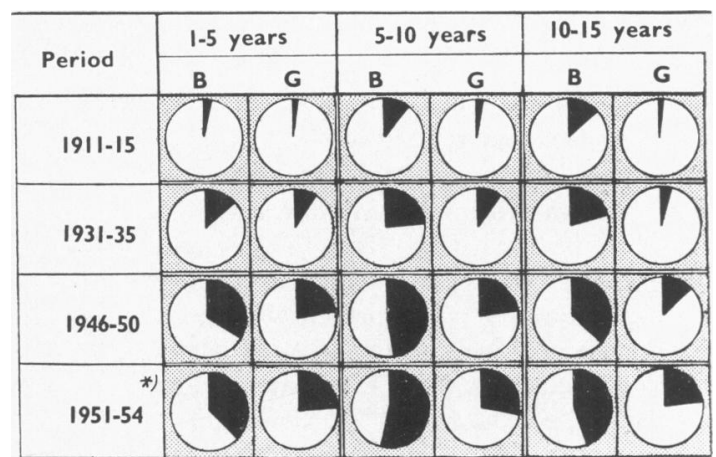

FiG. 1. $-B=$ boys. $\quad G=$ girls.

a first step an enquiry was made (Berfenstam, Ehrenpreis, Ekström, Garsten and Myrin, 1957) into all accidents in children (0-14 years) treated as in- or out-patients in all the hospitals of Stockholm during one year (1955). The number of children aged 0-14 years old in Stockholm is 227,000. The number of accidents among these children throughout the year 1955 was 24,466 and the number of deaths 29. Thus every tenth child had an accident during the year, which is a much higher morbidity rate than we had expected to find. It had been estimated earlier that every accidental death would correspond to between 100 and 400 non-fatal injuries. This investigation has given us the proportion as $1: 840$.

A rough estimate of the degree of severity of the injuries has been made according to whether the child was an in- or out-patient. Only 1,539 cases $(6.4 \%)$ were treated as in-patients.

Sex distribution showed a definite male predominance but not nearly as marked as for accidental deaths.

As for the time and place of the accidents, some interesting facts emerged. The hourly distribution shows a relatively high level between 10 a.m. and 8 p.m. with one small peak between 11 a.m. and noon and a definite maximum between 3 and 6 p.m.

* A paper read at the meeting of the British Association of Paediatric Surgeons held in Edinburgh in June, 1957. 
These are in Stockholm the hours just before luncheon and dinner time, respectively. In all probability the children are left alone during these hours more than at other times. Further it may be assumed that they are hungry and more irritable before meals than after, especially at dinner time. The afternoon peak is well known from earlier studies on industrial accidents. The distribution among week days is fairly even from Monday to Saturday, Sundays and holidays showing a decrease of about $20 \%$. A special study of road accidents shows the same daily distribution, which does not agree with earlier experience from studies on road accidents. This might be due to the fact that motor vehicles were involved in only $30 \%$ of our road accidents. In $66 \%$ of the road accidents, bicycles only were involved. The different months of the year show variations mainly in the accident pattern. The distribution of the various kinds of accidents and the various causes of accidental deaths do not correspond at all. The principal types of accidents were home accidents $(40 \%)$, school accidents $(28 \%)$ and road accidents $(10 \%)$; the main causes of death were road accidents $(34 \%)$, drowning $(31 \%)$ and suffocation $(10 \%)$. Home accidents were responsible for $0.35 \%$ of the deaths only and school accidents had no mortality at all.

A cautious estimate of annual community expenditure for medical care alone caused by childhood accidents gives a total of about $1 \cdot 25$ million swedish crowns in Stockholm with a population of about 1 million (227,000 children). To this we have to add family expenses for doctor's fees, transportation, loss of income, etc. Finally, the disaster produced by permanent disability or death is quite immeasurable. The magnitude of the problem is evident. A careful analysis of the information provided by this study may help us towards a future reduction of accident morbidity and prevention of its most serious results.

\section{Safety Measures}

A great number of things can be done to reduce the dangers in childhood. Most of these dangers are (in Sweden) localized to the roads, the waters and the homes.

Road accidents constitute one of the major problems of today in all civilized countries. Attempts to rouse public opinion are in progress everywhere and may prove to be our most important safety measure in this field. Others include sensible traffic regulations, supervision of small children and systematic training of pre-school and school children. More specific protection is offered by safety belts, special seats for baby passengers in cars and on bicycles, lockable car doors, etc. This field is in Sweden well covered by our National Society for Road Safety.

The principal safeguard against drowning is promotion of swimming ability, especially through the schools. During the last 10 years there has been a marked increase in the proportion of school children who know how to swim. This has resulted in a marked decrease in mortality from drowning. For the small children a very important thing is to have wells safely covered and closed.

The home at present seems to be the most dangerous place for our children, $40 \%$ of their accidents being home accidents. Two types of home accident are especially worthy of preventive efforts: burns and poisoning. The open fire is not nearly as important a cause of disaster in Sweden as in Great Britain: central heating actually seems to be a very good safety measure. Electric burns are very nasty. They are due to faulty electric equipment or to meddling with the electric outlets, especially with scissors or nails. A Swedish electrical firm (Joel Olsson, Stockholm) has devised an outlet, where the plug holes are covered by a valve, which opens for the appropriate 2-pin plug only after introducing it into the upper part of the receiver and bringing the valve downwards. The real plug-holes are then entered through the lower part of the receiver (Fig. 2).

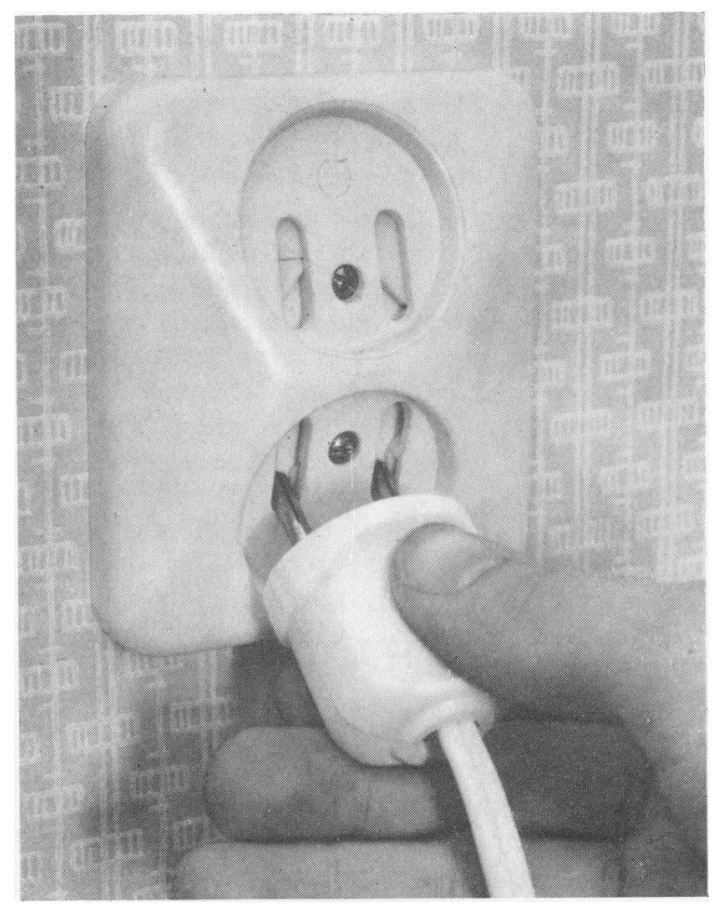

Fig. 2. 
The obvious safeguard against accidental poisoning is to keep every potential poison under lock and key. Some of these preparations may, however, be needed several times every day, especially cleaning agents, etc., and it would be very inconvenient to have them locked away. A rural policeman in southern Sweden has constructed a special safety catch for the cupboard door latch requiring two combined manœuvres before it opens. Experience has shown that toddlers may be very ingenious but they cannot do combined manœuvres, so this simple device is quite efficient.

The same principle has been used by a young Swedish paediatrician in devising a safety bottle-cap. It needs both inward pressure and twisting to open (Fig. 3a); if only unscrewed nothing happens (Fig. 3b). This safety cap ('nixi') (A. B. Termator, Stockholm) is available for all common sizes of bottlenecks and pill-boxes and costs very little.

\section{Informing the Public}

Our present knowledge of childhood accidents, however incomplete it may be, gives us more than sufficient cause for rousing public opinion. Every possible means should be used. The Swedish press, radio and television have been very cooperative. Besides these ordinary channels, we have been working out some special schemes. For many years we have had well-organized child welfare centres, where practically every infant is checked. Elementary information on the dangers in childhood

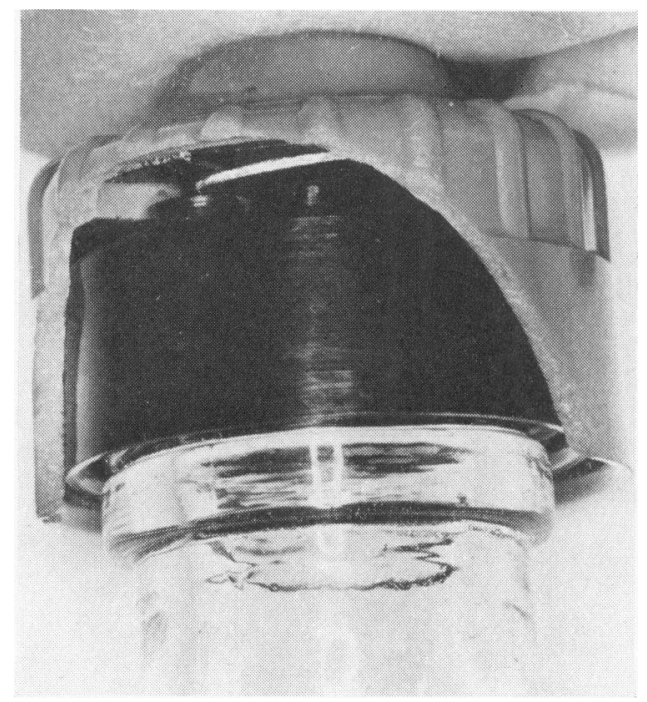

Fig. 3A. and appropriate safety measures are now included in their programmes.

An exhibition called the 'Dangerous World of Childhood' has been circulating for two years now through most of our major towns. Introductory lectures have been given by local paediatricians and surgeons. A popular booklet with the same title, besides serving as a programme to the exhibition, has been distributed to all mothers visiting the child welfare centres and has also been available through the bookstalls.

A series of posters is at present being displayed by the well-known surgical instrument makers, Stille-Werner, in cooperation with our Joint Committee.

Several films have been produced, among others a very good one on road accidents, 'To Kill a Child'. This film was awarded a prize at the Edinburgh Festival a few years ago and has recently been shown on British television.

Time only can tell to what extent our preventive efforts will be effective. It may sound paradoxical, but we do not expect and we do not even aim towards a material reduction of the total number of accidents. As stated before, the morbidity study in Stockholm 1955 showed that only $6.4 \%$ of the accidents caused more or less serious injuries. These injuries, and especially the potential causes of permanent disability or death, are the ones we are striving to prevent. Even a very good result within this limited scope would only slightly reduce the total number of accidents.

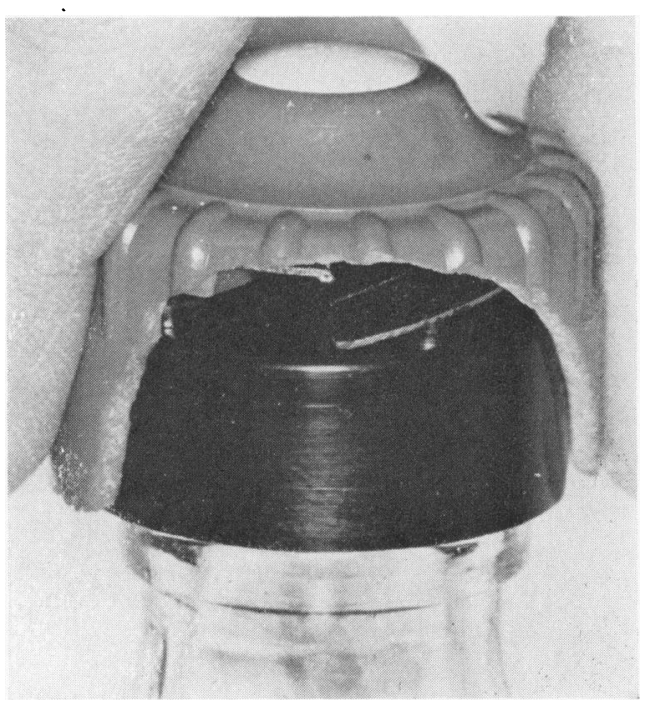

FIG. 3B. 
A further increase in our present mortality : to treat severely injured children. Most serious morbidity ratio of $1: 840$ would thus seem to be accidents are unnecessary and ought to be prevenour ideal reward.

One may well ask if this kind of work is within the scope of a paediatric surgeon. I would say definitely yes, and the reasons are two. First, any paediatric surgeon who has to treat a large number of injured children will soon realize that treatment of the individual case is not enough. These injuries repeat themselves in a monotonous way year in year out, and even the most successful treatment of the individual case leaves behind an apprehensive feeling of dissatisfaction. It would obviously be much better to prevent unnecessary accidents than table.

The second reason is that people who know the practical side of the problem should engage in this work in order to direct protective measures where they are most needed, even though accident prevention to a large extent may be part of social medicine. As most of childhood accidents are surgical cases there seems to be no person more fitted for this work than the paediatric surgeon.

REFERENCE

Berfenstam, R., Ehrenpreis, T., Ekström, G., Garsten, P. and Myrin, S. O. (1957). Svenska LäkT., 54, 1950. 